\title{
Actualidad
}

\section{HIGIENE DEL VESTIDO INFANTIL}

\author{
1) $r$. ERNESTO FIGUEROA R. *
}

Hospital Luis Calvo Mackenna

Cada día en el Consultorio Externo de $\mathrm{Me}-$ djcina, nos es dado comprobar cuán hondo es el desconocimiento que existe en la clientela hospitalaria respecto del rol que desempeñan los vestidos en la regulación del calor corporal.

Ellos son agentes físicos que utilizados científicamente producen comodidad y salud, pero mal empleados, son causa de molestias $y$ enfermedades.

Si analizamos a cada niño su ropa, es decir, el conjunto de vestidos que le cubren, advertimos que por lo general, tanto el número de piezas como su distribución y la elección de las telas, se ha hecho sin criterio científico alguno.

Hay la tendencia de abrigar exageradamente al recién naciđo y al lactante. En esta edad, el metabolismo acuoso es inestakle. El abrigo excesivo puede agravar o contribuir a la aparición de cuadros de deshidratación aguda. En otras edades, el "arropamiento" exagerado o uso de telas inadecuadas, producen sudoraciones abundantes que humedecen los vestidos $\mathrm{y}$ provocan al niño bruscos enfriamientos. Es ésta la causa de numerosisimas bronquitis a repetición.

Hay casos en que el uso de ropa interior, confeccionadas con cięrtas fibras textiles, producen afecciones cutáneas (dermatitis, etc.). Entre ellas citaremos al nylon.

Otras prendas de vestir, hechas con determinados materiales (cuero, goma, etc.), si bien es cierto que protegen la ropa de ser humedecida, obstaculizan, en cambio, las funciones fisiológicas de la piel.

Existe en el comercio una enorme variedad de telas. Sus nombres corresponden, en muchos casos, a marcas comerciales, otros, si bien son internacionales, no dan a conocer ni su estructura ni las propiedades físi-

\footnotetext{
- Jefe del Consultorio Externo.
}

cas de que están dotadas. Estas cualidades no dependen solamente de la naturaleza de las fibras textiles, empleadas en su confección, sino también del agrupamiento de ellas (tejidos), tratamientos a que han sido sometidos, tanto físicos (torsión, etc.), como químicos (mercerizado, apresto, teñido, ete.).

Su conocimiento es indispensable para poderlas emplear de una manera racional. Mas, para esto es imprescindible conocer el mecanismo físiológico de la regulación del calor corporal. Sólo así puede elegirse ropa que coopere a esta función y que no la entorpezca o suprima, acarreando graves daños al organismo. Desgraciadamente nuestro sistema educacional no capacita a la mujer para poder seleccionar para sus hijos ropa adecuada para cada edad, actividad y estación. Ella desconoce, además, los procesos fisiológicos a que nos hemos referido y las leyes que los rigen. Es preciso entonces, que sea el médico quien asuma el papel de educador.

La finalidad de los vesticis es defender al cuerpo humano de los ataques exteriores y colaborar a la regulación térmica, es decir, a que exista equilibrio entre la termogénesis $\mathrm{y}$ las pérdidas calóricas.

Vearnos primero cuáles son las fuentes del calor orgánico $v$ cómo los seres humanos se defienden del exceso de calor.

Las principales fuentes calóricas son:

a) Energía química contenida en los alimentos. La cantidad de calor depende de la intensidad de las oxidaciones celulares.

b) Transformación de la energía radiante cósmica. Las ondas electromagnéticas, al chocar contra un cuerpo, se transforman en calor. Esto es absorbido a través de la piel.

c) Calor emitido por cuerpos cuya tempe- 
ratura es mayor que la del cuerpo (calefacción, ingestión de bebidas calientes, baños tibios, etc.).

El organismo necesita, en ciertas circunstancias, aumentar y en otras, disminuir las pérdidas calóricas.

El primer caso se presenta cuando la temperatura ambiente es elevada (climas tropicales, días calurosos), ejecución de ejercicios o trabajos pesados, permanencia en locales mal ventilados, hacinamiento humano, exceso de calefacción, enfermedades febriles, etc., etc.

La necesidad de disminuir las pérdidas calóricas se presenta cuando la temperatura ambiente es baja '(estación invernal, días fríos, exposición a corrientes de aire, etc.).

El calor orgánico se pierde por:

1) Conducción;

2) Irradiación;

3) Convección, $y$

4) Evaporación.

La eliminación es proporcional a la superficie del cuerpo, a la diferencia entre su temperatura y la de los objetos que le rodean y a la humedad ambiente.

Explicaremos brevemente en qué consiste cada uno de estos procesos y cómo actúan.

Conducción. Es la transmisión por continuidad, del calor del organismo humano, a un cuerpo sólido, líquido o gaseoso. Se pierde calor por conducción, por ejemplo, cuando cogemos en nuestras manos un trozo de metal o hielo, cuando nos sentamos sobre el suelo frío, etc.

Irradiación. Todo cuerpo caliente tiende a compartir su calor con los objetos fríos que le rodean.

Convección. Las moléculas de un gas o de un líquido, calentadas por conducción, se desplazan $y$ ascienden. Son reemplazadas por otras más frias, situadas en las capas superiores. Se establece así una corriente que arrastra consigo el calor.

Evaporación. El paso del agua al estado gaseoso absorbe calor. La evaporación de la sudaración y respiración cutánea, en la superficie de la piel y la evaporación en el pulmón de la humedad del aire inspirado, sustraen calor al forganismo. Un litro de sudor, para evaporarse, requiere quinientas ochenta calorías. La intensidad de la evaporación es inversamente proporcional a la humedad del aire.

Hemos pasado en revista el origen del ca- lor orgánico y los procesos físicos que rigen su conservación y eliminación.

Veamos ahora el rol de la ropa frente a estos fenómenos biológicos.

Ella, en ciertos casos debe cooperar a la termogénesis $y$ en otros, obstaculizarla; a veces formentar las pérdidas de calor y otras veces, frenarlas.

Precisemos cómo es posible obtener objetivos tan diferentes. Para eso es necesario conocer:

A. Las fibras textiles;

B. Agrupamiento y ligazón de las fibras, es decir, estructura de los tejidos.

A. Fibras textiles. Según su origen se dividen en 4 grupos:

1) Vegetales;

2) Animales;

3) Artificiales o sintéticas, y

4) Minerales.

Vegetales: En esta categoría nos interesan las siguientes:

a) Lino: Sus fibras se emplean como material textil, desde la más remota antigïedad. Son resistentes y durables. Se cultivan en el sur de Chile. Las telas de lino son menos aisladoras que las confeccionadas con otras fibras textiles. Esto las hace apropiadas para ser empleadas en la ropa interior durante el verano. Los géneros hilados con las fibras más finas se denominan "batista".

b) Algodón: Se emplean los filamentos que constituyen la pelusa que envuelve la semilla. Su largo alcanza hasta 3 centímetros. Son higroscópicas, es decir, absorben agua. A fin de aumentar su resistencia y brillo, se le somete a procedimientos quími$\cos$ especiales ("mercerización") o físicos (retorcidos).

c) Otras fibras textiles de procedencia vegetal son: el yute, cáñamo, pita, abacá y ramio. Se emplea sólo para la confección de ciertas prendas de vestir (sombreros, zapatos, etc.).

Animales: El pelo suave $y$ rizado, obtenido por la "esquila", se denomina "lana". Está formada por filamentos revestidos de una capa de células aplanadas, que Je forman una envoltura. Pueden absorber agua, hasta el cuarenta por ciento de su peso.

La lana se obtiene de diferentes especies animales: ovejas (angora, merino), cabras (cachemira, etc.), alpaca, guanaco, vicuña, llama, camello, etc.

Su calidad varía en un mismo animal, se- 
gún las distintas regiones del cuerpo. La más apreciada es la que se obtiene de los flancos.

El grosor, la suavidad, longitud, resistencia, etc., dependen de las razas, climas, alimentación del ganado, etc.

La longitud de las fibras puede alcanzar hasta cuarenta centímetros de largo. Son menos resistentes que las de algodón, lino o seda natural.

Seda: La llamada seda natural está formada por los delgadísimos hilos que constituyen el capullo del gusano de seda. Son productos de una secreción que fluye por dos estrechos orificios, que este insecto posee cerca de la boca. Tratados por procedimientos especiales, aumentan su resistencia. La seda natural constituye la fibra textil más delgada, elástica, resistente y aisladora de que dispone el hombre.

Artificiales o sintéticas. Su fabricación constituye una industria de enorme importancia. Se le extrae de minerales plásticos o derivados de la celulosa. En este grupo citaremos los siguientes:

a) Nylon: Sus fibras son resistentes, fácilmente lavables, se secan con rapidez. Se alteran y deforman con el agua caliente. No absorben la transpiración ni permiten su evaporación.

b) Rayón: Se le obtiene de la celulosa. Sus fibras son resistentes, durables, lavables, soportan bien el lavado con agua caliente.

La seda artificial es menos resistente que la obtenida del capullo del gusano de seda.

Minerales. Las fíbras de este grupo no sirven para la confección de tejidos, debido a su fragilidad y escasa resistencia (lana de vidrio, etc.). Se emplea como material aislador (refrigeradores, "cocinas brujas").

Todas las fibras textiles, antes de sex hiladas, deben ser sometidas a diferentes procedimientos químicos y físicos, a fin de separar las materias extrañas (partículas vegetales, grasas, cera, goma, etc., etc.). Dada su extrema delgadez y fragilidad, es necesario reunir las fibras, en un largo filamento. Se denomina "hilado" o "hilo". Su calibre depende del número de fibras que le forman y del grado de torsión. Esto aumenta su resistencia y confiere a las telas determinadas propiedades físicas. Si el hilo es muy retorcido (popelina, tocuyo, etc.), la tela será poco higroscópica y poco elástica. Si la torsión es menos intensa, será un género absorbente, pero de menor resistencia (lienzo, etc.).

B. Agrupamiento y ligazón de las fibras, es decir, estructura de los tejidos.

Los hilos pueden ser combinados entre sí, formando diferentes variedades. Ellas dan origen a las distintas clases de tejidos. En algunos el hilo va entrelazado sobre sí mismo: "tejido de punto". Una variedad de él es el tejido casero, hecho a "crochet".

En otros casos, ciertos hilos están dispuestos longitudinalmente (urdimbre) y van entretejidos, con hilos transversales (trama).

Hay otras variedades, en las cuales al tipo de tejido citado anteriormente, se agregan hilos que corren en otras direcciones. Esto da origen a géneros gruesos y tupidos (terciopelos, felpa, etc.).

La tela después de tejida, es sometida a ciertos procedimientos químicos. Algunos están destinados ya sea a darle brillo, otros, resistencia (mercerizado), determinado color (teñido), o aumentar sus propiedades aisladoras. Entre estos últimos citaremos e1 "cardado". Los géneros así tratados, presentan en una de sus caras (franela) o en ambas (moletón), una superficie frisada, suave e irregular, formada por un complejo entrecruzamiento de filamentos que forman pequeñas celdillas que aumentan el volumen de aire retenido. Estos géneros están dotados de una mayor capacidad aisladora. Son muy abrigadores y están destinados a ser usados durante la estación invernal o días fríos.

Las principales propiedades físicas de las telas y que nos interesan, desde el punto de vista de la higiene del vestido, son las siguientes:

a) Conductibilidad térmica;

b) Permeabilidad al aire;

c) Poder higroscópico, y

d) Capacidad reflectora.

El grado de intensidad de cada una de ellas se expresa por coeficientes numéricos.

Explicaremos cada una de ellas:

a) Conductibilidad térmica: Expresa la capacidad aisladora.

La irradiación de un individuo vestido es proporcional a la superficie cutánea descubierta, a la temperatura orgánica, a la diferencia térmica que existe entre ella y el ambiente $y$ a la conductibilidad de las telas con las cuales está confeccionada su ropa.

El calor es eliminado en forma de radia- 
ciones infrarrojas, a través de la piel. Estas radiaciones, al pasar a través de los vestidos, son rechazadas en mayor o menor proporción.

El poder aislador de un género depende del volumen de aire retenido entre sus mallas, del grosor y de la naturaleza de las fibras textiles.

El aire que ocupa los intersticios, situados entre los hilos, no está sometido a las leyes de la irradiación, ni de la convección.

En las telas lisas y de trama apretada (popelinas, tocuyos, etc.), el tamaño de estos poros es pequeño y la cantidad de aire es escasa. El poder aislador es menor. Por esta cualidad se emplean para la confección de ropa de verano. En cambio, las telas frisadas (moletón, franela, etc.) y las gruesas, especialmente aquellas cuyos hilos se entrecruzan en distintas direcciones (terciopelo, felpa, etc.), retienen mayor volumen de aire. Son más aisladoras. Se usan en vestidos de invierno o de días fríos.

Los géneros fofos y porosos (tejidos de punto), son los más abrigadores. En el verano, a fin de aumentar la irradiación calórica, se disminuye la superficie cubierta por la ropa. Asf se usan blusas sin mangas, pantalones cortos, vestidos escotados, etc. Además, se escogen telas delgadas.

El uso de diferentes prendas de vestir deja entre cada una de ellas una cantidad de aire que aumenta la capacidad aisladora de la ropa. Si ésta es estrecha y ajustada, el volumen de aire es menor.

Si tomamos como unidad la conductibilidad del aire a cero grados y exploramos la radiación calórica, por centímetro cuadrado. en la unidad de tiempo y en telas de un centímetro de espesor, encontramos los siguientes coeficientes de conductibilidad:

$\begin{array}{lr}\text { Lana } & \mathbf{6} \\ \text { Seda } & 18 \\ \text { Algodón } & 28 \\ \text { Lino } & \mathbf{3 0}\end{array}$

Estos valores nos permiten deducir que son los tejidos de lana los más adecuados para el invierno y los de seda, algodón y lino los indicados para la estación estival (tejidos frescos).

Mas, la conductibilidad de un tejido textil no es constante. Ella se modifica si un líquido desplaza al aire de los intersticios. Las telas aumentan su conductibilidad. E] individuo cuya ropa está humedecida pierde rápidamente calor y sufre bruscas y gra- ves hipotermias. A este fenómeno físico se le designa en el lenguaje popular con el nombre de "enfriamiento de la transpiración". Su causa no es sólo la pérdida del aire tisular, sino también, la desaparición de una cape de aire, que normalmente existe entre la piel y los vestidos. Puede evitársele, si se tiene la precaución de abrigar, a todo individuo que termina de ejecutar un ejercicio, un trabajo muscular violento o abandona un local muy calefaccionado, a fin de contrarrestar la buena conductibilidad de la ropa mojada.

La lana empapada experimenta un aumento de $109,8 \%$ de su poder conductor, la seda un $41 \%$ y el algodón un $16 \%$. Estos coeficientes señalan las ventajas del uso de ropa interior de algodón.

Muchas madres tienen la costumbre de colocar a los niños, durante la edad de la lactancia, algunas prendas de vestir impermeables (calzones de goma, trozos de hule). Con esto no sólo se pretende evitar que se humedezcan los vestidos vecinos, sino también, el enfriamiento, provocado por la presencia de las ropas mojadas y la pérdida de calor producida por la evaporación. Son estas aplicaciones prácticas de principios físi$\cos$ que acabamos de citar. Desgraciadamente, el empleo de prendas de vestir impermeables presenta serias desventajas. Suprime la aireación y ventilación cutánea, lo cual produce maceraciones que predisponen a afecciones cutáneas; crea condiciones favorables para la exagerada proliferación de la flora bacteriana, que transforma la urea de Ia orina en amoníaco. lo cual produce rebeldes dermatitis y se obstaculiza, además, uno de los principales mecanismos de la regulación calórica: la evaporación sudoral.

El uso simultáneo de 2 ó 3 pañales tiene por finalidad disminuir las pérdidas de calor. El segundo y tercer pañal (mantilla) se confeccionan en géneros "afranelados" (franela, moletón). La gran proporción de aire contenida entre las mallas de estas telas las hace altamente malas conductoras y capaces, aun estando húmedas, de aminorar el enfriamiento del niño.

Es frecuente observar que numerosos individuos combaten el ascenso de la temperatura orgánica, provocada por un esfuerzo físico o por calor ambiental, despojándose bruscamente de una o varias prendas de ropa exterior. Por lo general, rapida- 
mente se experimenta una sensación de intenso frío y acompañado aun de escalofríos. Su explicación es clara: torpemente se han retirado aquellas prendas que, por ser de lana o por estar secas, contrarrestaban la exagerada conductibilidad de la ropa interior, humedecida por la sudoración.

Permeabilidad al aire. Los intersticios de las mallas de los tejidos están ocupados por el aire. Estos microscópicos espacios permiten la aireación de la piel, la evaporación de la respiración y secreción sudoral.

Se llama "coeficiente de permeabilidad" el número de segundos que tarda en pasar el aire a una presión dada, a través de un pedazo de tela de un centímetro cuadrado de superficie $y$ de un centímetro de grueso.

El aire retenido en los poros de un tejido textil, es más rico en anhidrido carbónico que el aire libre. $\mathrm{Su}$ determinación es otro indice de la permeabilidad de un género.

La evaporación de la transpiración aumenta con la ventilación. Es proporcional a la temperatura e inversamente proporcional a la humedad del aire. Si el ambiente es húmedo y la temperatura alta, el organismo humano experimenta una desagradable sensación de malestar. Hay aumento de calor corporal y pueden presentarse casos de insolación.

Si un líquido desplaza al aire de los intersticios de un tejido, éste pierde su permeabilidad. Esta circunstancia se presenta cuando la ropa se moja con la transpiración. Desaparece así, para el agua contenida en la sudoración, Ia posibilidad de escaparse a través de los poros de los vestidos, al estado de vapor. Se produce un ascenso de la temperatura corporal $y$ un mavor aumento de la secreción sudoral, con lo cual se obtiene una mayor conductibilidad de los vestidos y mayor pérdida de calor.

Las telas de poros anchos y consistencia fofa poseen mejor "coeficiente de permeabilidad" que los géneros lisos, de trama apretada, hechos con hilados retorcidos.

La ventilación (corriente de aire, etc.) favorece $y$ aumenta la permeabilidad textil. Debido a esto, en los climas fríos y con fuertes vientos, debe usarse por encima de un vestido, confeccionado con una tela de poros anchos, otra prenda hecha de un género liso $y$ de trama apretada.
La pérdida de la permeabilidad puede demostrarse prácticamente en el lavado de la ropa. Al remover, en ura arteza, una tela mojada, el aire queda aprisionado, formando "bolsas" que actúan como verdaderos flotadores.

Dijimos que la ventilación favorece la evaporación sudoral. Nuestras clases populares saben por experiencia cuán peligrosos son los bruscos descensos de la temperatura orgánica que se producen en aquellos individuos que con las ropas empapadas por la sudoración, se colocan en sitios muy ventilados (corrientes de aire, cumbres de montañas, etc.).

Los repetidos lavados y el uso disminuye la permeabilidad de los tejidos. Al principio la trama se hace más apretada y luego con el roce, los hilos se adelgazan.

Indice higroscópico. Traduce la capacidad absorbente para el vapor de agua. Su intensidad depende de la naturaleza de las fibras textiles, de los procesos físicos a que ha sido sometida (torsión, etc.), estructura de los tejidos y humedad del aire.

Es la lana la fibra textil más higroscópica, le sigue en orden decreciente la seda $y$ finalmente el algodón.

Una tela se empapa más rápidamente mientras menor sea su impregnación por el "apresto", más toscos sean los hilados empleados en su confección y más suelta la trama del tejido.

Las fibras que absorben poco la hurnedad, retienen mejor el calor del cuerpo.

Las telas afraneladas, aún húmedas, conservan siempre cierta cantidad de aire tisular.

EI indice higroscópico de las telas tiene enorme importancia. El actúa sobre la conductibilidad y permeabilidad de los tejidos.

Durante la lactancia las frecuentes micciones hacen necesario el uso de telas capaces de absorber la orina. El primer pañal, - sea aquel que está en contacto con la piel, generalmente es de lienzo. Se elige esta tela por su mayor poder de inbibición, debido a que los hilados están poco retorcidos. Los otros pañales, además de su capacidad absorbente, deben estar dotados de gran propiedad aisladora.

Tienen una mayor capacidad de inbibición, no sólo las telas cuyos hilados son poco retorcidos, sino también aquellas de trama suelta. Los frecuentes lavados aumen- 
$\tan$ ?a propiedad higroscópica de algunas telas, pues hacen desaparecer el "apresto". Mas, en otros casos, disminuye, pues con el agua la trama se hace más apretada.

El índice higroscópico de los géneros tiene gran importancia en los climas calurosos.

Indice reflector. Se refiere a la capacidad de absorción o rechazo de las radiaciones cósmicas.

El color juega un rol fundamental. Los géneros blancos $\mathrm{y}$ de tonos claros son los que reflejan en mayor proporción las radiaciones solares. Los colores negros y oscuros las absorben en su totalidad o en gran proporción. Durante el verano, especialmente en los climas calurosos debe elegirse telas de colores blancos y de tonos oscuros en invierno. La seda es material textil más impenetrable a los rayos ultravioleta $\mathrm{y}$ aún a los rayos $\mathrm{X}$.

Expondremos a continuación una lista de los géneros más comunes y daremos alơunos pormenores de sus características y detalles de su estructura.

Sólo conocidos estos antecedentes, es posible su empleo en una forma racional.

Lienzo. Es una tela de algodón, hecha con hilados finos poco retorcidos. Es liviana, blanca y suave al tacto. Se le utiliza para la confección de ropa interior (camisitas, pañales, etc.).

Tocuyo. Tela de algodón hecha con hilados toscos y retorcidos. Es cruda, de mayor cuerpo y peso aue el lienzo. Es un poco áspera.

Los lavados repetidos la blanquean y le dan suavidad.

Por su menor costo y mayor duración, aconsejamos su empleo para la confección de ropa interior de las clases asaJariadas.

opal. Género delgado, de algodón, hecho con hilos finos. Se le emplea para ropa interior.

Batista. Es una tela delgada, confeccionada con hilos finísimos de algodón o lino. Se le emplea para pañales, etc. Es caro.

Popelina. Tela delgada de hilados retorcidos de algodón mercerizado (con brillo) o seda natural o artificial (rayón). Suave al tacto. Se usa para ropa interior (camisas, blusas, etc.).

Jersey. Género de punto, un poco elástico. Estos tejidos están formados por un solo hilo que se va entrelazando consigo mismo. Puede ser de seda, lana, algodón, o mezclas de estas fibras textiles. Se le uti- liza para ropa interior (calzoncillos, camisetas, etc.) o exterior (blusas, etc.).

Franela. Es una tela en la cual sólo los hilos longitudinales son retorcidos, no así los transversales. Es igual al tocuyo, pero está frisada por un lado. Esto le da una especial suavidad. La superficie vellosa debe colocarse en contacto con la piel. Gracias a las vellosidades es posible la aireación y evaporación de la transpiración. Es abrigadora, pues la frisa aumenta la cantidad de aire aprisionado entre sus mallas. Se le emplea para ropa interior o exterior.

Moletón. Es análoga a la franela, pero frisada por ambos lados. Es muy abrigadora $\mathrm{y}$ suave. Se usa para la confección de paitocitos, blusas y pañales.

Hilo. Tela confeccionada con hilos finos de algodón, retorcidos. Según el grosor de ellos, la tela es más delgada o gruesa. La más fina se emplea para ropa interior, panuelos, blusas, etc. La más gruesa se usa para sábanas. El hilado retorcido, se utiliza también para la confección de calcetines.

Lino. Es un género hecho con hilados de esta fibra vegetal. Se produce en el sur de Chile. Las fibras más finas se seleccionan para la confección de géneros destilados para ropa interior. Es una tela resistente, fría y más tosca que los tejidos delgados de algodón.

Madepolan. Género blanco, tupido y de regular grosor. Se usa para delantales, paltocitos, etc.

Piqué. Tela de algodón, de regular grueso, con rayitas, motas, canales o listas sobresalientes, hechas del mismo tejido. Puede ser de hilos mercerizados: Hay de diferentes colores. Se le utiliza para paltocitos, blusas, vestidos de verano.

Nido de abeja. Género de algodón, generalmente es blanco. Se asemeja a un panal, es decir, presenta cavidades octogonales. Se usa para paltocitos.

Gamuza. Es una tela de algodón, suavemente raspada para darle especial suavidad. Si es delgada puede utilizarse para ropa interior, para la estación fría. Si es gruesa, sirve para ropa exterior.

Crea. Tela de algodón, tejida con hilados retorcidos, se diferencia del tocuyo por el ancho. Se le utiliza para sábanas.

Viyela. Tela de algodón de estructura similar a la franela, pero tiene más hilado por centímetro cuadrado. Hay una clase frisada $y$ otra lisa. Se le utiliza para la confección de ropa de dormir. 